\title{
Purification of Marine Bacterial Sialyltransferases and Sialyloligosaccharides
}

\author{
Toshiki Mine and Takeshi Yamamoto \\ Glycotechnology Business Unit, Japan Tobacco Inc., \\ Japan
}

\section{Introduction}

Sialic acids are important components of carbohydrate chains and are usually found at the terminal position of the carbohydrate moiety of glycoconjugates (Angata \& Varki, 2002; Schauer, 2004). Sialyloligosaccharides of glycoconjugates play important roles in many biological processes (Gagneux \& Varki, 1999; Varki, 1993). The transfer of sialic acids to carbohydrate chains is performed by specific sialyltransferases in the cell (Angata \& Varki, 2002; Vimr et al., 2004). Thus, sialyltransferases are considered to be key enzymes in the biosynthesis of sialylated glycoconjugates. Detailed investigations of the biological functions of sialylated glycoconjugates require an abundant supply of the target compounds. To date, many sialyltransferases, and the genes encoding them, have been isolated from various sources including mammalian, bacterial, and viral sources (Schauer, 2004; Sujino et al., 2000; Yamamoto et al., 2006). During our research, we have isolated over 20 bacteria that produce sialyltransferase and have revealed the characteristics of these enzymes (Kajiwara et al., 2009; Yamamoto, 2010). In this chapter, we will introduce our research activities focusing on methods for (1) screening bacteria for glycosyltransferase activity; (2) purifying native sialyltransferases from marine bacteria; and (3) synthesizing and purifying sialyloligosaccharides produced by marine bacterial sialyltransferases.

Sialic acid is a family of acidic monosaccharides comprising over 50 naturally occurring derivatives of neuraminic acid (5-amino-3,5-dideoxy-D-glycero-D-galacto-2-nonulosonic acid or Neu) (Angata \& Varki, 2002; Vimr et al., 2004). Structurally, sialic acid is one of the more complicated naturally occurring monosaccharides and is based on a skeleton of nine carbons (Schauer, 2004). $N$-acetylneuraminic acid (Neu5Ac), N-glycolylneuraminic acid (Neu5Gc), and 2-keto-3-deoxy-D-glycero-D-galacto-nonulosonic acid (deaminoneuraminic acid, KDN), are the three most common members of this family (Angata \& Varki, 2002; Schauer, 2004). The structure of Neu, Neu5Ac, Neu5Gc and KDN are shown in Figure 1. Although sialic acid is widely distributed in higher animals and some classes of microorganisms, only Neu5Ac is ubiquitous (Angata \& Varki, 2004). Usually, sialic acid exists in the carbohydrate moiety of glycoconjugates, including glycoproteins and glycolipids, and is linked to the terminal positions of the carbohydrate chains of the glycoconjugates. Many studies have been carried out to clarify the structure-function relationship of carbohydrate chains containing sialic acid. These studies have revealed that Neu5Ac is the most common sialic acid component of carbohydrate chains and sialylated carbohydrate chains of 
glycoconjugates play significant roles in many biological processes including inflammation, glycoprotein clearance from circulation, cell-cell recognition, cancer metastasis, and virus infection (Kannagi, 2002; Paulson, 1989). Sialyltransferases commonly transfer Neu5Ac from cytidine 5'-monophospho- $N$-acetylneuraminic acid (CMP-Neu5Ac) to various acceptor substrates (Angata \& Varki, 2002). Thus, sialyltransferases are thought to be one of the important enzymes in the biosynthesis of sialylated glycoconjugates.

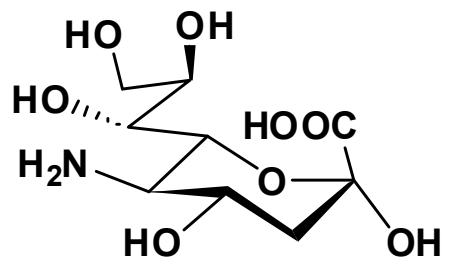

(A)

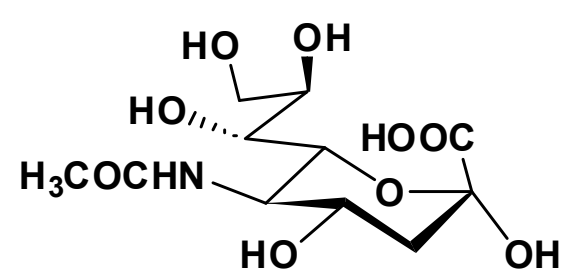

(B)

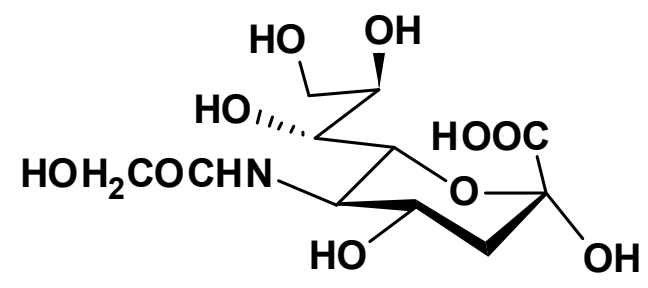

(C)

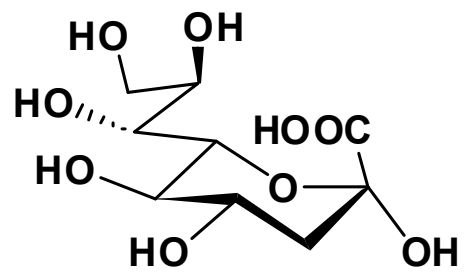

(D)

(A) Neuraminic acid (Neu), (B) N-acetylneuraminic acid (Neu5Ac), (C) N-glycolylneuraminic acid (Neu5Gc), (D) deaminoneuraminic acid (KDN).

Fig. 1. Structures of sialic acids.

Among the biological phenomena described above, the relationship between the carbohydrate chain structure of the host cell and host cell recognition by influenza virus is one of the best investigated (Suzuki, 2005; Weis et al., 1988). Many reports have shown that influenza A and B viruses bind via viral hemagglutinin to host cell surface receptors that are Neu5Ac- or Neu5Gc-linked glycoproteins or glycolipids (Suzuki, 2005). Furthermore, these influenza viruses also recognize the carbohydrate chain structure of the host cell (Connor et al., 1994). Confirming evidence has shown that avian influenza viruses recognize Neu5Ac $\alpha 2-3 G a 1 \beta 1-3 / 4 G l c N A c$ structures, and that human influenza viruses recognize Neu5Aca2-6GalB1-3/4GlcNAc structures (Connor et al., 1994; Suzuki, 2005). The host cell specificities of the influenza $A$ and $B$ viruses are determined mainly by the linkage of Neu5Ac or Neu5Gc to the penultimate galactose residues and core structure of the host glycoproteins or glycolipids. For this reason, the distribution of Neu5Ac and Neu5Gc and their linkage patterns on the host cell surface are important determinants of host tropism.

A large variety of oligosaccharides exist in nature. For example, many kinds of sialyloligosaccharides, such as 3'-sialyllactose, 6'-sialyllactose, and sialyllacto- $N$-neotetraose, are contained in milk of various animals (Kunz et al., 2000); however, the purification and isolation of sialyloligosaccharides from natural sources is very difficult due to their structural complexity. Therefore, the research use and development of drugs that depend on 
sialyloligosaccharides relies on sialyloligosaccharide synthesis by chemical or enzymatic methods. Although many methods for the synthesis of sialyloligosaccharides including chemical- and enzyme-based methods using glycosyltransferases have been developed, it is still difficult to synthesize large amounts of sialyloligosaccharides. Therefore, only a limited amount and only a few kinds of sialyloligosaccharides are currently available as research reagents. In this chapter, we introduce our results with regard to methods for screening for bacterial glycosyltransferases, purification of native sialyltransferases from bacteria, and the synthesis and purification of sialyloligosaccharides produced by marine bacterial sialyltransferases. The methodologies introduced in this chapter might to be useful for screening of bacteria that produce other types of glycosyltransferases, purification of membrane-binding proteins, and purification of oligosaccharides.

\section{Screening bacteria for sialyltransferase activity}

\subsection{Basic screening method}

Samples of seawater, sea-sand, mud, seaweed, and small animals including various kinds of fishes and shells, were collected from various coastal locations in Japan. Bacteria that grew on marine agar 2216 or nutrient agar (Becton-Dickinson, Franklin Lakes, NJ, USA) that was supplemented with $2 \% \mathrm{NaCl}$ at $15^{\circ} \mathrm{C}, 25^{\circ} \mathrm{C}$, or $30^{\circ} \mathrm{C}$ were isolated from the samples. Aliquots of the bacteria were suspended in $10 \%$ glycerol and stored at $-80^{\circ} \mathrm{C}$. For each bacterial isolate, $6 \mathrm{~mL}$ of marine broth 2216 (Becton-Dickinson) in a 15-mL test tube was inoculated with bacteria and cultivated at $15^{\circ} \mathrm{C}, 25^{\circ} \mathrm{C}$, or $30^{\circ} \mathrm{C}$ for $18 \mathrm{~h}$ on a rotary shaker (180 rpm). After the cultivation, bacteria were harvested from 2 to $4 \mathrm{~mL}$ of the culture broth by centrifugation and then suspended in $200 \mu \mathrm{L}$ of $20 \mathrm{mM}$ sodium cacodylate buffer $(\mathrm{pH}$ 6.0) that contained $0.2 \%$ Triton X-100, lysed by sonication on ice, and measured immediately for sialyltransferase activity. Sialyltransferase activity was confirmed as follows: the reaction mixture $(30 \mu \mathrm{L})$ consisted of the bacterial lysate as the sample of enzyme, $120 \mathrm{mM}$ lactose, 2.3 mM CMP-Neu5Ac (Nakarai Tesque, Kyoto, Japan), 4620 Bq CMP-[4,5,6,7,8,9-14C]Neu5Ac (Amersham Biosciences, Little Chalfont, UK), $100 \mathrm{mM}$ Bis-Tris buffer ( $\mathrm{pH}$ 6.0), 0.5 $\mathrm{M} \mathrm{NaCl}$, and $0.03 \%$ Triton $\mathrm{X}-100$. The reaction was carried out at $25^{\circ} \mathrm{C}$ for $2 \mathrm{~h}$. The reaction mixture was then diluted with $5 \mathrm{mM}$ sodium phosphate buffer $(\mathrm{pH} 6.8)$ to a final volume of $2 \mathrm{~mL}$, and applied to a column $(0.5 \times 2 \mathrm{~cm})$ of Dowex- $1 \times 8$ (phosphate form, Bio-Rad Laboratories, Hercules, CA, USA). The eluate $(2 \mathrm{~mL})$ was collected directly into a scintillation vial for counting. The radioactivity of $[4,5,6,7,8,9-14 \mathrm{C}]-\mathrm{Neu} 5 \mathrm{Ac}$ that had transferred to the acceptor substrate in the eluate was measured by using a liquid scintillation counter, and the amount of Neu5Ac transferred was calculated. Unreacted CMP-Neu5Ac was not eluted in this buffer concentration. Using this procedure, we have isolated many bacteria that possess sialyltransferase activity. Many of the marine bacteria that produced sialyltransferases were classified in genus Photobacterium or the closely related genus Vibrio. For instance, Photobacterium phosphoreum JT-ISH-467 that showed $\alpha 2,3-$ sialyltransferase activity was isolated from the outer skin of Japanese common squid, Todarodes pacificus (Tsukamoto et al. 2007); Photobacterium damselae JT0160 that expressed $\alpha 2,6$-sialyltransferase activity was isolated from seawater (Yamamoto et al., 1998); Photobacterium sp. JT-ISH-224 that contained both $\alpha 2,3$ - and $\alpha 2,6$-sialyltransferase activities was isolated from the gut of Japanese barracuda, Sphyraena pinguis (Tsukamoto et al., 2008); and Photobacterium leiognathi JT-SHIZ-145 that expressed $\alpha 2,6$-sialyltransferase activity was isolated from the outer skin of Japanese squid, Loliolus japonica (Yamamoto et al., 2007). 


\subsection{Simultaneous measurement of several glycosyltransferases activities}

To assess the activities of various glycosyltransferases, not only sialyltransferases, we performed the enzyme assay using a mixture of the donor substrates of glycosyltransferases (GDP-fucose, the common donor substrate of fucosyltransferase; UDP-galactose, the common donor substrate of galactosyltransferase; and UDP-GlcNAc, the common donor substrate of $\mathrm{N}$ acetyl-glucosaminyltransferase), and a mixture of the acceptor substrates of glycosyltransferases (4-Nitrophenyl a-D-galactopyranoside \{Gal-a-pNp\}; 4-Nitrophenyl $\beta$-Dgalactopyranoside $\{$ Gal- $\beta$-pNp\}; 4-Nitrophenyl $N$-acetyl-a-D-galactosaminide $\{$ GalNAc-apNp\}; 4-Nitrophenyl $N$-acetyl- $\beta$-D-galactosaminide $\{$ GalNAc- $\beta$-pNp\}; 4-Nitrophenyl $N$-acetyla-D-glucosaminide $\{$ GlcNAc-a-pNp\}; 4-Nitrophenyl N-acetyl- $\beta$-D-glucosaminide $\{$ GlcNAc- $\beta$ $\mathrm{pNp}\}$; 4-Nitrophenyl a-D-glucopyranoside $\{$ Glc- $\alpha-\mathrm{pNp}\}$; 4-Nitrophenyl $\beta$-D-glucopyranoside $\{$ Glc- $\beta$-pNp\}; 4-Nitrophenyl $\alpha$-L-fucopyranoside $\quad\{$ Fuc- $\alpha-p N p\} ; \quad 4-N i t r o p h e n y l \quad \beta$-Lfucopyranoside $\{$ Fuc- $\beta$-pNp\}; 4-Nitrophenyl $\alpha$-D-mannopyranoside $\{$ Man- $\alpha-p N p\}$; and 4Nitrophenyl $\beta$-D-mannopyranoside $\{$ Man- $\beta-p N p\})$, and bacterial lysate described in 2.1 as the enzyme sample. An example of results obtained by using this method is shown in Figure 2.

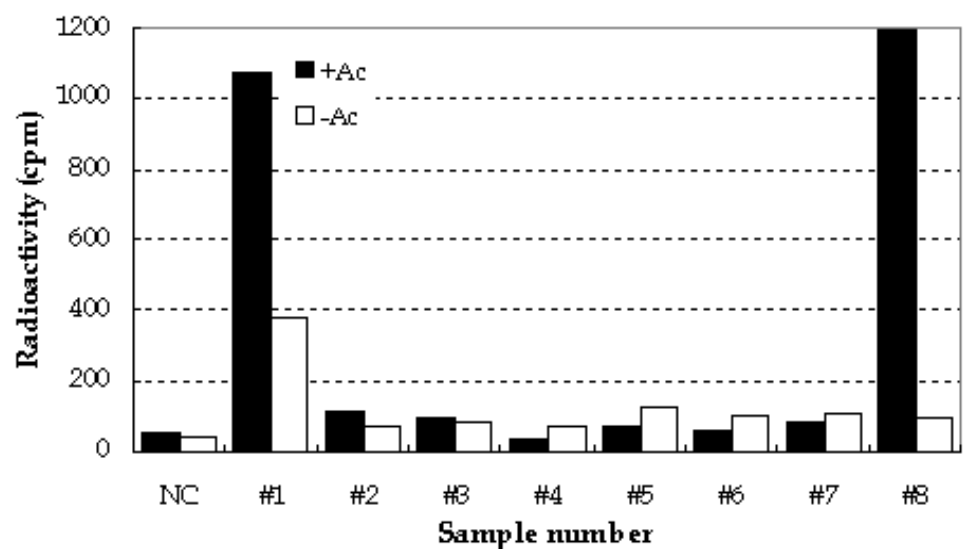

Fig. 2. Screening assay for glycosyltransferase activities.

High levels of radioactivity were observed in the eluates from the reaction mixture of samples \#1 and \#8, respectively, when the reaction was performed in the presence of acceptor substrate. From this result, it was strongly expected that lysates prepared from bacteria number \#1 and \#8 contained fucosyltransferase, galactosyltransferase and/or $\mathrm{N}$ acetylglucosaminyltransferase. NC; negative control, $+\mathrm{AC}$; containing acceptor substrate mixture in the reaction mixture, $-\mathrm{AC}$; no acceptor substrate mixture in the reaction mixture.

The reaction mixture $(50 \mu \mathrm{L})$ consisted of the following: a sample of enzyme, a mixture of 0.5 $\mathrm{mM}$ acceptor substrates consisting of 4-nitrophenyl compounds, as described above, a mixture of $0.5 \mathrm{mM}$ donor substrates consisting of sugar-nucleotides as described above, 4620 Bq UDP-[U-14C]-galactose, 4620 Bq UDP-N-acetyl-D-[U-14C]-glucosamine, 4620 Bq GDP-[U$\left.{ }^{14} \mathrm{C}\right]$-fucose (Amersham Biosciences, Little Chalfont, UK), $100 \mathrm{mM}$ bis-Tris buffer (pH 6.0), 10 $\mathrm{mM} \mathrm{MnCl}$, and $3 \mathrm{mM}$ ATP. The reaction was carried at $25^{\circ} \mathrm{C}$ for 16 to $18 \mathrm{~h}$. After the reaction, $100 \mu \mathrm{L}$ of water was added to the reaction mixture, and the mixture was applied to a Sep-Pac Vac 50cc column (Waters, Milford, MA, USA) that was conditioned with ethanol and equilibrated with water. The column was washed twice with $1 \mathrm{~mL}$ of water and the 
reaction product was eluted with $1 \mathrm{~mL}$ of $70 \%$ ethanol. One millilitre of scintillation cocktail was added to the eluate, and the radioactivity of the mixture was measured by using a liquid scintillation counter. In this way, we could detect glycosyltransferase activities, comprising fucosyltransferase, galactosyltransferase and/or $N$-acetylglucosaminyltransferase activity, simultaneously in marine bacteria. To clarify which of the glycosyltransferase activities the bacteria displayed, the enzymatic reaction was performed independently with each of the donor substrates in turn. The two bacteria that showed glycosyltransferase activity in Figure 2 were shown to specifically produce fucosyltransferase.

\subsection{Screening by lectin staining}

Lectins are sugar-binding proteins that are highly specific for their sugar moieties. The lectin Sambucus sieboldiana agglutinin (SSA) recognizes the Neu5Aca2-6Gal or Neu5Aca2-6GalNAc structure of sialyloligosaccharides in glycoconjugates (Shibuya et al., 1989). Kajiwara et al. carried out lectin staining of the cells of $P$. damselae JT0160, P. leiognathi JT-SHIZ-145, P. phosphoreum JT-ISH-467, and Photobacterium sp. JT-ISH-224, by using biotin-labeled SSA, and then examined the cells by using differential interference contrast (DIC) and fluorescence microscopy (Kajiwara et al., 2010). Lectin staining was carried out as follows: the 4 bacterial species described above were cultivated in nutrient broth supplemented with $2 \%(\mathrm{w} / \mathrm{v}) \mathrm{NaCl}$ at $25^{\circ} \mathrm{C}$ for $18 \mathrm{~h}$ on a rotary shaker. The bacterial cells were collected by centrifugation $(8,000 g$, $15 \mathrm{~min}, 4^{\circ} \mathrm{C}$ ) and suspended in $25 \mathrm{mM}$ Tris- $\mathrm{HCl}$ buffer $8(\mathrm{pH} \mathrm{7.5)}$. The suspensions were spotted onto glass slides, fixed with a $4 \%(\mathrm{w} / \mathrm{v})$ paraformaldehyde solution at room temperature for $15 \mathrm{~min}$, and blocked with a $5 \%(\mathrm{w} / \mathrm{v})$ bovine serum albumin (BSA) phosphate-buffered saline (PBS) solution. After the glass slides were washed, biotin-labeled SSA ( $5 \mathrm{mg} \mathrm{mL}^{-1}$ ) was added and the cells were incubated at room temperature for $2 \mathrm{~h}$. After the cells were washed 4 times with PBS, Alexa 594-labeled streptavidin (Invitrogen, Carlsbad, CA, USA) solution ( $5 \mathrm{mg} \mathrm{mL}^{-1}$ ) was added and the incubation was continued at room temperature for $1 \mathrm{~h}$. After 5 washes with PBS, the cells were mounted using Prolong Gold antifade reagent (Invitrogen) and observed by using DIC and fluorescence microscopy. The SSA bound to Photobacterium sp. JT-ISH-224, P. damselae JT0160, and P. leiognathi JT-SHIZ-145. These Photobacterium strains produce $\alpha 2,6$-sialyltransferases, so the lectin staining indirectly detected $\alpha 2,6$-sialyltransferase-producing bacteria (Fig. 3). SSA did not bind to P. phosphoreum JT-ISH-467, which produces only $\alpha 2,3$-sialyltransferase. Therefore, the SSA lectin might be useful to screen for not only Neu5Aca2-6Gal and/or Neu5Aca2-6GalNAc structures on the bacterial cell surface but also to screen for the production of $\alpha 2,6$-sialyltransferase. We consider that this method would be applicable to the screening of other glycosyltransferases by changing the type of lectin used. We have confirmed that one of the two bacteria that showed fucosyltransferase activity, described in section 2.2, was detected by biotin-labeled Aleuria aurantia lectin (AAL, from Seikagaku Kogyo), which recognizes the fucose residue in carbohydrate chains (Kochibe \& Furukawa, 1980).

\section{Purification of sialyltransferase from the native bacterium}

For the purification of a protein, it is necessary and important to find the appropriate conditions for enzyme solubilization, including solubilization efficiency, and the most efficient combination of chromatography processes. Each process has a different separation mode, and it is crucial to conduct a detailed study of the conditions required for each process. Crude extracts are commonly used in such studies, but care must be taken to 


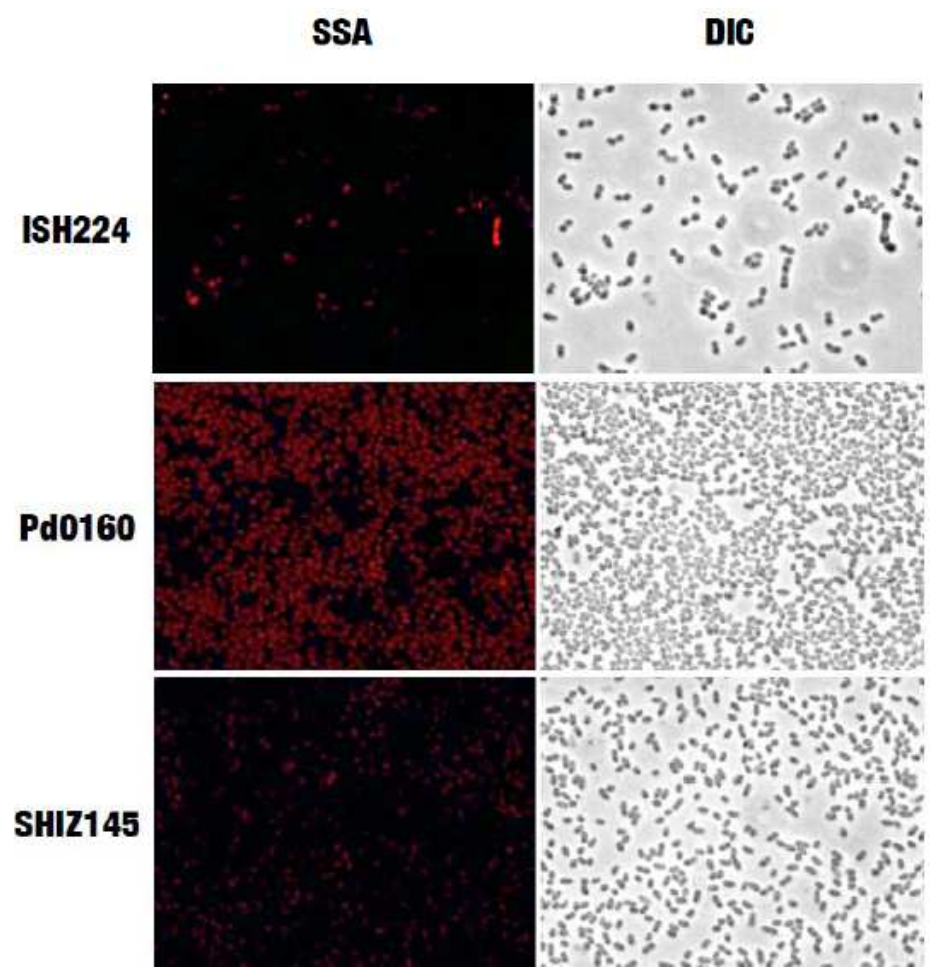

ISH224, Photobacterium sp. JT-ISH-224; Pd0160, P. damselae JT0160; SHIZ145, P. phosphoreum JT-SHIZ145; SSA, fluorescence microscopy of cells stained with Sambucus sieboldiana agglutinin (SSA); DIC, differential interference contrast microscopy of the cells shown in the SSA panels.

Fig. 3. Lectin staining of Photobacterium strains by Sambucus sieboldiana agglutinin.

minimize protease activity, which may decompose the target enzyme. Furthermore, it is necessary to consider the $\mathrm{pH}$ of the buffers used in the purification steps as well as the temperature employed during the preparation of the extracts and the purification process. For details of general procedures and methods for protein purification, we recommend that you refer to other textbooks (e.g., Deutscher, 1990; Scopes,.1982). Here, we describe examples of the purification of sialyltransferase from marine bacteria.

\subsection{Purification of $\alpha 2,6$-sialyltransferase from P. damselae JT0160}

\subsubsection{Preparation of the crude extract from $P$. damselae cells}

The first step in the purification of a protein is the preparation of an extract containing the protein in a soluble form. During the purification of sialyltransferase from $P$. damselae, we examined in detail the conditions for preparing a crude extract containing the target enzyme in a soluble form (Yamamoto et al., 1998). The method that we established was deemed appropriate for the preparation of a crude extract containing sialyltransferase because no decrease in sialyltransferase activity was detected during the procedure. We determined that the most important factor in the preparation of the crude extract was the timing of the 
cell lysis after cultivation. For instance, almost no sialyltransferase activity was detected in crude extract prepared from cryopreserved cells of $P$. damselae. The procedure for crude extract preparation was as described below.

1. After cultivation, P. damselae JT0160 cells were harvested from the culture by centrifugation $(6,000 \mathrm{~g}, 20 \mathrm{~min})$.

2. The harvested cells were suspended in $20 \mathrm{mM}$ sodium cacodylate buffer $(\mathrm{pH} 6.0)$ containing $0.2 \%$ Triton X-100 and $1 \mathrm{M} \mathrm{NaCl}$, and were sonicated immediately $\left(<4^{\circ} \mathrm{C}\right)$ until the absorbance at $660 \mathrm{~nm}$ reached $30 \%$ or less of that of the original cell suspension.

3. The sonicated solution was centrifuged $(100,500 \mathrm{~g}, 60 \mathrm{~min})$ and the supernatant was dialyzed, using cellulose tubing, against $20 \mathrm{mM}$ sodium cacodylate buffer ( $\mathrm{pH}$ 6.0) containing $0.2 \%$ Triton X-100.

4. After dialysis, the precipitate was removed by centrifugation $(100,500 \mathrm{~g}, 60 \mathrm{~min})$ to obtain the clarified extract.

\subsubsection{Purification of sialyltransferase by using column chromatography}

Sialyltransferase produced by $P$. damselae was then purified from the crude extract by a combination of 4 steps of column chromatography. The conditions and method used for each chromatography step are described below.

1. Q-Sepharose column chromatography. A column of Hi-Load 26/10 Q Sepharose HP (ø $2.6 \times 10 \mathrm{~cm}$; GE Healthcare Science, Buckinghamshire, UK) was equilibrated with $20 \mathrm{mM}$ sodium cacodylate buffer ( $\mathrm{pH}$ 6.0) containing $0.2 \%$ Triton X-100. Clarified extract was applied to the column, and the column was washed with $150 \mathrm{~mL}$ of the same buffer. Enzyme fractions were eluted with a linear gradient of 0 to $1 \mathrm{M} \mathrm{NaCl}$ in the buffer. The fractions exhibiting sialyltransferase activity ("active" fractions) were collected and pooled. Desalting of the "active" fractions was performed by dialysis, using cellulose tubing, against $20 \mathrm{mM}$ sodium cacodylate buffer ( $\mathrm{pH}$ 6.0) containing $0.2 \%$ Triton X-100.

2. Hydroxyapatite column chromatography. A column of hydroxyapatite $(\varnothing 2 \times 10 \mathrm{~cm}$; Bio-Rad Laboratories) was equilibrated with $20 \mathrm{mM}$ sodium cacodylate buffer ( $\mathrm{pH}$ 6.0) containing $0.2 \%$ Triton X-100. After the application of the enzyme solution obtained in step 1, the column was washed with the same buffer. The enzyme fraction was eluted with a gradient of 0 to $0.35 \mathrm{M}$ potassium phosphate. The "active" fractions were collected and pooled, and then concentrated by ultrafiltration using Molecut $\mathrm{L}$ (exclusion molecular mass, $10 \mathrm{kDa}$; Millipore, Billerica, MA, USA).

3. Gel-filtration column chromatography. A column of Hi-Load 26/60 Sephacryl S-200 HE (ø $2.6 \times 60 \mathrm{~cm}$; GE Healthcare Science, Buckinghamshire, UK) was equilibrated with 20 $\mathrm{mM}$ sodium cacodylate buffer ( $\mathrm{pH}$ 6.0) containing $0.2 \%$ Triton X-100 and $0.1 \mathrm{M} \mathrm{NaCl}$. The enzyme solution obtained in step 2 was applied to the column and eluted with the same buffer. The "active" fractions were collected and pooled. Desalting of these fractions was performed by dialysis, using cellulose tubing, against $20 \mathrm{mM}$ sodium cacodylate buffer ( $\mathrm{pH}$ 6.0) containing $0.2 \%$ Triton X-100.

4. CDP-hexanolamine-agarose column chromatography. A column of CDPhexanolamine-agarose $(\varnothing 1 \times 3 \mathrm{~cm})$ was equilibrated with $20 \mathrm{mM}$ sodium cacodylate buffer ( $\mathrm{pH}$ 6.0) containing $0.2 \%$ Triton X-100. The enzyme solution ( $4 \mathrm{~mL}$ ) obtained in step 3 was applied to the column. The column was washed with $8 \mathrm{~mL}$ of the same buffer. The enzyme was eluted with $6 \mathrm{~mL}$ of $2 \mathrm{M} \mathrm{NaCl}$, and "active" fractions were collected and pooled. 
The purity and yield of the enzyme at each step is summarized in Table 1.

\begin{tabular}{lcccccc}
\hline Purification step & $\begin{array}{c}\text { Volume } \\
(\mathrm{mL})\end{array}$ & $\begin{array}{c}\text { Total protein } \\
(\mathrm{mg})\end{array}$ & $\begin{array}{c}\text { Total activity } \\
(\mathrm{U})\end{array}$ & $\begin{array}{c}\text { Specific activity } \\
(\mathrm{U} / \mathrm{mg})\end{array}$ & $\begin{array}{c}\text { Yield } \\
(\%)\end{array}$ & $\begin{array}{c}\text { Purification } \\
(\mathrm{fold})\end{array}$ \\
\hline \hline Crude extract & 760 & 2584 & 21.1 & 0.008 & 100 & 1 \\
Q Sepharose & 240 & 552 & 12.4 & 0.022 & 59 & 2.8 \\
Hydroxyapatite & 120 & 85 & 8 & 0.094 & 38 & 11.8 \\
Sephacryl S-200 & 30 & 20.1 & 6.7 & 0.3 & 32 & 37.5 \\
CDP-hexanolamine-agarose & 15 & 0.75 & 4.1 & 5.5 & 19 & 687.5 \\
\hline
\end{tabular}

Table 1. Purification of sialyltransferase from cell lysate of Photobacterium damselae.

The enzyme was purified 688 -fold, with a yield of $19 \%$. The purified enzyme migrated as a single polypeptide with a molecular mass of $61 \mathrm{kDa}$ by SDS-polyacrylamide gel electrophoresis under denaturing conditions.

\subsection{Purification of $\alpha 2,3$-sialyltransferase from $P$. phosphoreum JT-ISH-467}

\subsubsection{Preparation of the crude extract from $P$. phosphoreum cells}

The crude extract containing sialyltransferase from $P$. phosphoreum cells was prepared by the method described in section 3.1.1, with slight modifications (Tsukamoto et al., 2007), and then crude extract containing the soluble form of the enzyme was prepared.

\subsubsection{Purification of sialyltransferase from $P$. phosphoreum by using column chromatography}

Sialyltransferase produced by $P$. phosphoreum was purified from the crude extract by a combination of 5 steps of column chromatography. The conditions and method used for each of the column chromatography steps are described below.

1. DEAE column chromatography. The clarified crude extract was applied to a Hi-Prep 16/10 DEAE FF column $(\varnothing 1.6 \times 10 \mathrm{~cm}$; GE Healthcare Science) equilibrated with $20 \mathrm{mM}$ bis-Tris buffer ( $\mathrm{pH}$ 6.0) containing $0.3 \%$ Triton X-100. After the column was washed with the same buffer, the enzyme was eluted with a linear gradient of 0 to $1 \mathrm{M} \mathrm{NaCl}$ in the same buffer. The fractions with sialyltransferase activity were pooled and then diluted to three times the original volume with $20 \mathrm{mM}$ potassium phosphate buffer $(\mathrm{pH}$ 6.0) containing $0.3 \%$ Triton $X-100$.

2. Hydroxyapatite column chromatography. The enzyme solution obtained in step 1 was applied to a hydroxyapatite column $(\varnothing 1.5 \times 11.3 \mathrm{~cm}$; Bio-scale CHT20-I; Bio-Rad Laboratories) that was equilibrated with $20 \mathrm{mM}$ potassium phosphate buffer ( $\mathrm{pH}$ 6.0) containing $0.3 \%$ Triton X-100. After the column was washed with the same buffer, the enzyme was eluted with a linear gradient of 20 to $500 \mathrm{mM}$ potassium phosphate. The "active" fractions were pooled, and then diluted to two times the original volume with $20 \mathrm{mM}$ potassium phosphate buffer ( $\mathrm{pH}$ 6.0) that contained $0.3 \%$ Triton X-100.

3. Mono Q column chromatography ( $\mathrm{pH}$ 6.0). The enzyme solution obtained in step 2 was loaded onto a column of Mono Q 10/100 GL (ø $1 \times 10 \mathrm{~cm}$; GE Healthcare Science) that was equilibrated with $20 \mathrm{mM}$ potassium phosphate buffer $(\mathrm{pH} 6.0)$ containing $0.3 \%$ Triton X-100. After the column was washed with the same buffer, the enzyme was 
eluted with a linear gradient of 0 to $1 \mathrm{M} \mathrm{NaCl}$ in the same buffer. The "active" fractions were pooled, and then diluted to three times the original volume with $20 \mathrm{mM}$ bis-Tris buffer ( $\mathrm{pH} 7.0$ ) containing $0.3 \%$ Triton X-100.

4. Mono Q column chromatography ( $\mathrm{pH}$ 7.0). The enzyme solution obtained in step 3 was applied to a column of Mono Q 10/100 GL equilibrated with $20 \mathrm{mM}$ bis-Tris buffer ( $\mathrm{pH}$ 7.0) containing $0.3 \%$ Triton X-100. After the column was washed with $20 \mathrm{mM}$ bis-Tris buffer ( $\mathrm{pH} 7.0$ ) containing $0.3 \%$ Triton X-100, the enzyme was eluted with a linear gradient of 0 to $1 \mathrm{M} \mathrm{NaCl}$ in the same buffer. The "active" fractions were pooled.

5. Superdex 200 column chromatography. The enzyme solution obtained in step 4 was loaded onto Hi-Load 16/60 Superdex 200 pg $(\varnothing 1.6 \times 60 \mathrm{~cm}$; GE Healthcare Science) that was equilibrated with $20 \mathrm{mM}$ bis-Tris buffer ( $\mathrm{pH} 7.0$ ) containing $0.3 \%$ Triton X-100 and $0.2 \mathrm{M} \mathrm{NaCl}$ and eluted with the same buffer. The "active" fractions were collected and pooled.

The results for the purification of the enzyme are summarized in Table 2.

\begin{tabular}{lcccccc}
\hline Purification step & $\begin{array}{c}\text { Volume } \\
(\mathrm{mL})\end{array}$ & $\begin{array}{c}\text { Total protein } \\
(\mathrm{mg})\end{array}$ & $\begin{array}{c}\text { Total activity } \\
(\mathrm{U})\end{array}$ & $\begin{array}{c}\text { Specific activity } \\
(\mathrm{mU} / \mathrm{mg})\end{array}$ & $\begin{array}{c}\text { Yield } \\
(\%)\end{array}$ & $\begin{array}{c}\text { Purification } \\
(\text { fold })\end{array}$ \\
\hline \hline Crude extract & 3155 & 6159 & 8.40 & 1.4 & 100 & 1 \\
DEAE & 410 & 932 & 3.10 & 3.4 & 37 & 3 \\
Hydroxyapatite & 264 & 153 & 1.30 & 8.2 & 15 & 6 \\
Mono Q (pH 6.0) & 12 & 24 & 0.96 & 39 & 11 & 29 \\
Mono Q (pH 7.0) & 1.5 & 1.7 & 0.52 & 315 & 6.2 & 29 \\
Superdex 200 & 1.5 & 0.2 & 0.10 & 457 & 1.2 & 333 \\
\hline
\end{tabular}

Table 2. Purification of sialyltransferase from cell lysate of $P$. phosphoreum.

The enzyme was purified 333-fold, with a yield of $1.2 \%$. Because no affinity chromatography step was used, the yield of the protein purification in this case was very low. Therefore, preparing affinity gels with the appropriate ligand for the target enzyme is very important in the purification process.

\section{Enzymatic synthesis and purification of sialyloligosaccharides}

\subsection{Synthesis of sialyloligosaccharides by recombinant sialyltransferases from marine bacteria}

Chemoenzymatic synthesis of various sialyloligosaccharides by mammalian sialyltransferases, and the purification of the product, has been reported (Sabesan \& Paulson, 1986). However, mass-production of sialyloligosaccharides by using mammalianderived sialyltransferases remains problematic because the enzymes are unstable and difficult to produce as recombinant proteins in Escherichia coli. In comparison to mammalian sialyltransferases, bacterial sialyltransferases are generally more stable and productive in $E$. coli protein-expression systems (Tsukamoto et al., 2007, 2008; Yamamoto et al., 2006), and they show a broader acceptor substrate specificity (Izumi \& Wong, 2001; Yu et al., 2005). Here, we report the methods that we developed to use recombinant sialyltransferases from marine bacteria to successfully produce large quantities of 6 '-sialyllactose and synthesize various sialyloligosaccharides. 


\subsubsection{Synthesis of 6'-sialyllactose from lactose and CMP-Neu5Ac by using purified recombinant $\alpha 2,6$-sialyltransferase from $P$. damselae JT0160}

Purified recombinant $\alpha 2,6$-sialyltransferase from P. damselae JT0160 shows broader acceptor substrate specificity than that of the mammalian enzymes. For example, it could transfer Neu5Ac to not only disaccharides but also mono- and tri-saccharides efficiently, and provided the corresponding sialosides (Fig. 4; Kajihara et al., 1996; Yamamoto et al., 1998).

Below, we describe an example of the enzymatic synthesis of 6 -sialyllactose (sialoside 1 ).

1. The reaction mixture was composed of $20 \mathrm{mg}(55 \mu \mathrm{mol})$ of lactose (Gal $\beta 1-4 \mathrm{Glc}), 79 \mathrm{mg}$ $(110 \mu \mathrm{mol})$ of CMP-Neu5Ac, and $0.6 \mathrm{U}$ of the purified enzyme in $0.5 \mathrm{~mL}$ of $100 \mathrm{mM}$ bisTris buffer ( $\mathrm{pH}$ 6.0).

2. The reaction mixture was incubated at $30^{\circ} \mathrm{C}$ for $2 \mathrm{~h}$.

3. The product formed by the enzymatic reaction was analyzed by using thin layer chromatography (TLC) as follows: a small amount of the enzymatic reaction mixture was applied to a pre-coated silica gel plate (60 F254, Merck, Darmstadt, Germany), which was then developed with 2-propanol/acetic acid/water (3:2:1 v/v); for visualization of the organic compounds, the plate was dipped into a solution of $5 \% \mathrm{v} / \mathrm{v}$ sulfuric acid in ethanol and then heated.

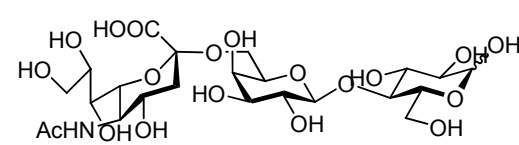

(A)

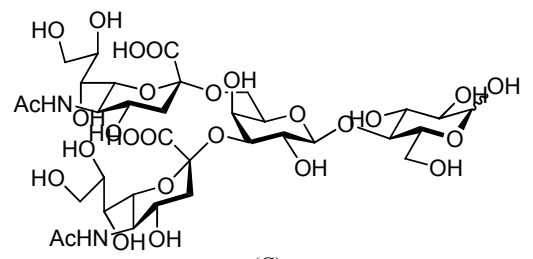

(C)

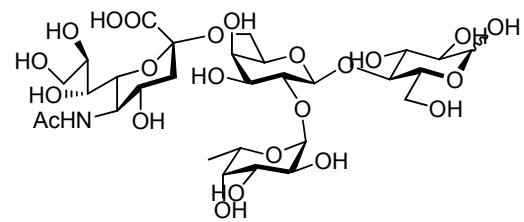

(B)

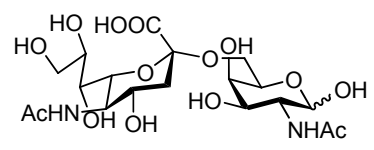

(D)

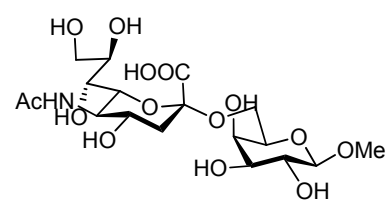

(E)

(A) 6'-sialyllactose (sialoside 1), (B) 2'-fucosyl-6'-sialyllactose (sialoside 2), (C) 3', 6'-disialyllactose (sialoside 3), (D) 6-sialyl- $N$-acetylgalactosamine (sialoside 4), (E) 6-sialyl-methyl- $\beta$-D-galactopyranoside (sialoside 5).

Fig. 4. Structures of sialosides 1-5.

\subsubsection{In vivo synthesis of 6'-sialyllactose by using genetically engineered $E$. coli}

Recently, we succeeded in mass-producing 6'-sialyllactose by using a genetically engineered E. coli strain expressing the Photobacterium sp. JT-ISH-224 gene for $\alpha 2,6$-sialyltransferase 
(Drouillard et al., 2010). Our method was developed from a microbiological system for the large-scale production of 3'-sialyllactose that used high cell-density cultures of a genetically engineered E. coli strain expressing the Neisseria meningitidis gene for $\alpha 2,3$-sialyltransferase (Fierfort \& Samain, 2008). To date, we have achieved the production of 6 '-sialyllactose with a final concentration greater than $30 \mathrm{~g} \mathrm{~L}^{-1}$ of culture medium, by continuously feeding the culture with an excess of lactose. A detailed report of the production conditions is provided in Drouillard et al. (2010).

\subsubsection{Synthesis of various sialyloligosaccharides by using purified recombinant $\alpha 2,3-$ sialyltransferase from Photobacterium sp. JT-ISH-224}

Using the procedure described in section 4.1.1, we could enzymatically produce 3'sialyllactose (sialoside 6) by using $\alpha 2,3$-sialyltransferase instead of $\alpha 2,6$-sialyltransferase. While using a recombinant $\alpha 2,3$-sialyltransferase derived from Photobacterium sp. JT-ISH-224 to produce 3 -sialyllactose, we detected a by-product in the enzymatic reaction mixture and determined its structure to be 2,3'-disialyllactose (sialoside 7; Mine et al., 2010a). This recombinant $\alpha 2,3$-sialyltransferase can also transfer Neu5Ac from CMP-Neu5Ac to the $\beta$ anomeric hydroxyl groups of mannose and 6-mannobiose to produce sialosides $8 \& 9$, respectively (Mine et al., 2010b), and transfer Neu5Ac to inositols to produce sialosides 10 \& 11 (Mine et al., 2010c). The structures of sialosides 6-11 are shown in Figure 5.

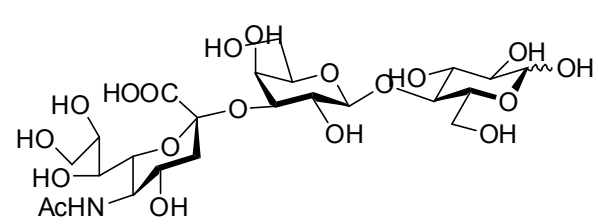

(A)

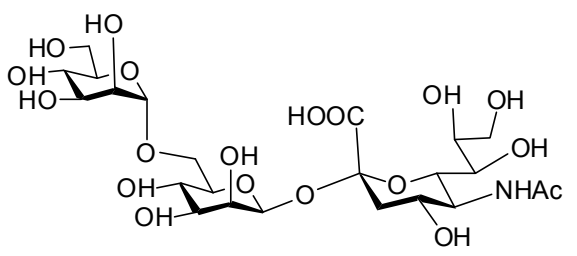

(C)

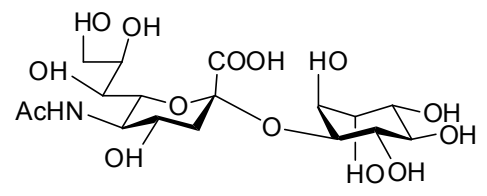

(E)

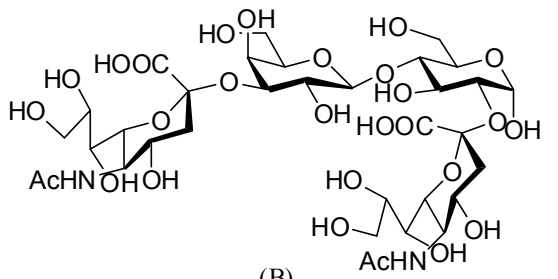

(B)

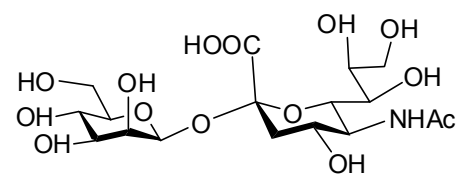

(D)

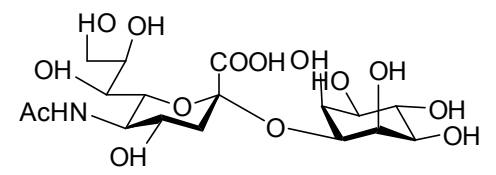

(F)

(A) 3'-sialyllactose (sialoside 6), (B) 2, 3'-disialyllactose (sialoside 7), (C) sialyl-6-mannobiose (sialoside 8), (D) sialyl-mannose (sialoside 9), (E) sialyl-1D-chiro-inositol (sialoside 10), (F) sialyl-epi-inositol (sialoside 11).

Fig. 5. Structures of sialosides 6-11. 


\subsection{Purification of sialyloligosaccharides by use of column chromatography}

In general, for the separation of oligosaccharides, it is convenient to utilize highperformance liquid chromatography (HPLC), and various types of columns, such as reversephase columns, ion-exchange columns, and gel-filtration columns, that are commercially available. Because Neu5Ac is negatively charged, it is comparatively easy to separate sialyloligosachharide(s) from other neutral oligosaccharides by using anion-exchange column chromatography (Sabesan \& Paulson, 1986). For further purification of the compound, gel-filtration column chromatography is effective.

The conditions and method used for each column chromatography step are described below.

\subsubsection{Separation of the sialyloligosaccharide and unreacted substrates from the enzymatic reaction mixture}

The basic procedure for anion-exchange column chromatography is as follows:

1. The reaction mixture was diluted with $10 \mathrm{~mL}$ of deionized water and introduced onto an Econo column $(\varnothing 1.0 \mathrm{~cm} \times 10 \mathrm{~cm}$; Bio-Rad Laboratories) containing AG1-X2 ionexchange resin (phosphate form; 200-400 mesh).

2. The column was washed with 3 column volumes $(\sim 30 \mathrm{~mL})$ of deionized water.

3. Elution of the sialyloligosaccharide was performed twice with $10 \mathrm{~mL}$ each of 5, 10, 50, 100,500 , or $1000 \mathrm{mM}$ potassium phosphate buffer ( $\mathrm{pH}$ 6.8).

4. An aliquot of each eluted fraction was analyzed by using TLC, as described in section 4.1.1.

The column volume required for separation is dictated by the scale of the synthetic reaction. For $10 \mathrm{mg}$ or less of acceptor substrate, all of the reaction product will bind to the resin described above. For more than $100 \mathrm{mg}$ of acceptor substrate, it is desirable to either perform the chromatography process at least twice, or to increase the amount of resin by using a larger column (e.g., ø $2.5 \mathrm{~cm} \times 10 \mathrm{~cm}$ ).

An example of results obtained for the separation of sialyloligosaccharide by using the above procedure is shown in Figure 6.

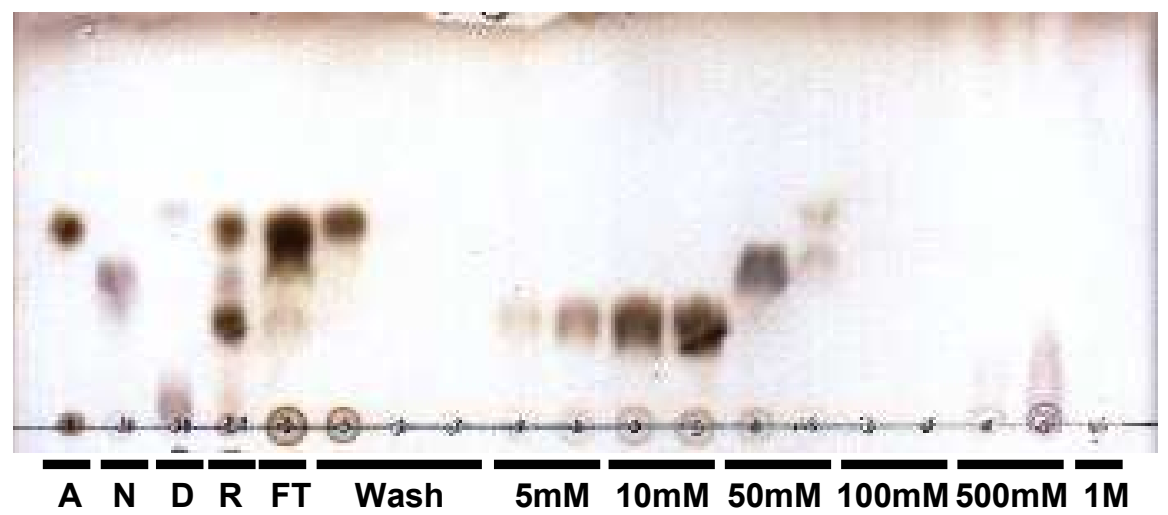

Fig. 6. TLC analysis of fractions separated by using anion-exchange column chromatography. 
The reaction solution after enzymatic reaction of substrates with recombinant $\alpha 2,6-$ sialyltransferase from $P$. damselae JT0160 strain contained unreacted lactose and CMPNeu5Ac, free Neu5Ac as result of hydrolysis of CMP-Neu5Ac, and the product. The contents of the fractions eluted with 5, 10, 50, 100, 500, and $1000 \mathrm{mM}$ potassium phosphate buffer ( $\mathrm{pH}$ 6.8) are shown. A, lactose; N, Neu5Ac; D, CMP-Neu5Ac; R, reaction solution after enzymatic reaction; FT, flow-through.

Many mono-sialyloligosaccharides composed of di-, tri- or tetra-saccharide eluted with 5 to $10 \mathrm{mM}$ potassium phosphate buffer. We also demonstrated that disialyloligosaccharides, such as sialosides 3 (Fig. 4) and 7 (Fig. 5), eluted with $100 \mathrm{mM}$ potassium phosphate buffer. In contrast, many of the unreacted acceptor substrates passed through the column because of their electrically neutral property. Unreacted CMP-Neu5Ac and free Neu5Ac, resulting from the hydrolysis of CMP-Neu5Ac during the reaction, were eluted with 500 and $50 \mathrm{mM}$ potassium phosphate buffer, respectively (Fig. 7). Therefore, it is easy to separate these compounds in the enzymatic reaction mixture with this column chromatography process.

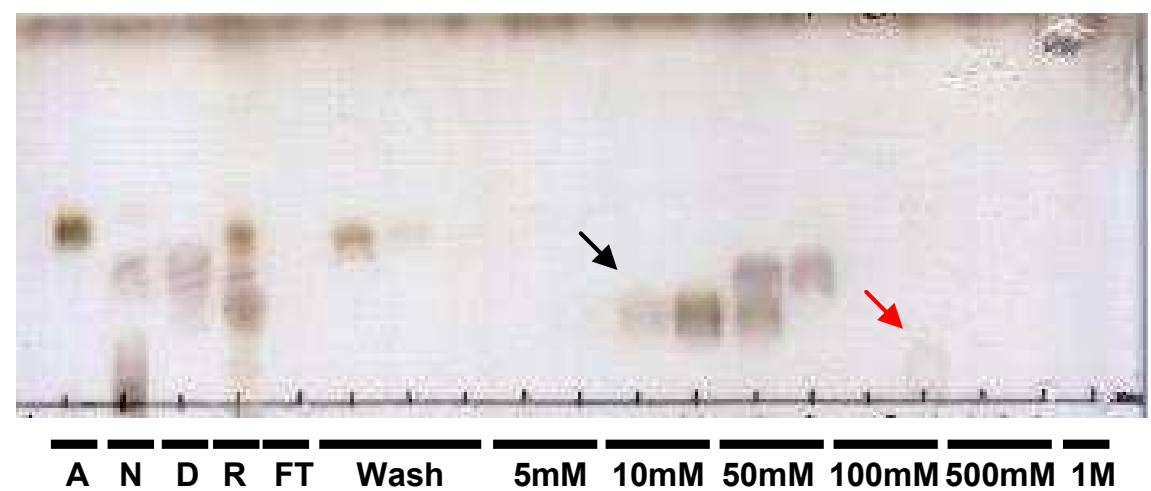

Fig. 7. Separation of mono-sialyloligosaccharide and di-sialyloligosaccharide from the reaction solution by using anion-exchange column chromatography.

The reaction solution after enzymatic reaction with recombinant $\alpha 2,3$-sialyltransferase from Photobacterium.sp. JT-ISH-224 strain contained unreacted lactose, CMP-Neu5Ac, free Neu5Ac, and both the mono-sialyloligosaccharide (sialoside 6) as main product (black arrow) and the di-sialyloligosaccharide (sialoside 7) as by-product (red arrow). The contents of the fractions eluted with 5, 10, 50, 100, 500, and $1000 \mathrm{mM}$ potassium phosphate buffer $(\mathrm{pH}$ 6.8) are shown. A, lactose; N, Neu5Ac; D, CMP-Neu5Ac; R; reaction solution after enzymatic reaction, FT, flow-through.

During the stepwise elution described above, we sometimes observed that both the reaction product and free Neu5Ac were present in the same fraction. In this case, the separation of these compounds can be improved by increasing the volume of $10 \mathrm{mM}$ potassium phosphate buffer (e.g., using 3-5 column volumes of the buffer).

This basic procedure for the separation of sialyloligosaccharide in the enzymatic reaction mixture is more effective when the enzyme reaction produces a single monosialyloligosaccharide. If the reaction mixture contains a variety of mono-sialyloligosaccharides, it is preferable to perform the preparative chromatography using a different column, such as TSKgel Amide-80 (Tosoh Bioscience, Tokyo, Japan) (Endo et al., 2009). 
For further purification of the sialyloligosaccharide, we performed gel-filtration column chromatography. The procedure is as follows:

1. The fractions containing glycosidic Neu5Ac were evaporated to dryness.

2. The dried residue was dissolved in $2.5 \mathrm{~mL}$ of deionized water and then loaded onto a Sephadex G-15 column $(\varnothing 1.6 \times 70 \mathrm{~cm})$ and eluted with deionized water under a 2.5 $\mathrm{mL} / \mathrm{min}$ flow rate and collected in increments of $1 \mathrm{~mL}$.

3. The fractions containing glycosidic Neu5Ac were pooled and evaporated to dryness.

The purpose of this process is to remove salt carried from the former chromatography process. The product was eluted in the $30^{\text {th }}$ to $50^{\text {th }}$ fractions (Fig. 8). When Neu5Ac was mixed with the product, it could be separated from the product under a lower flow rate (e.g., $1.0 \mathrm{~mL} / \mathrm{min}$ ). The purity of sialyloligosaccharides obtained by using a combination of the two chromatography processes described above is usually more than 95\% (data not shown).
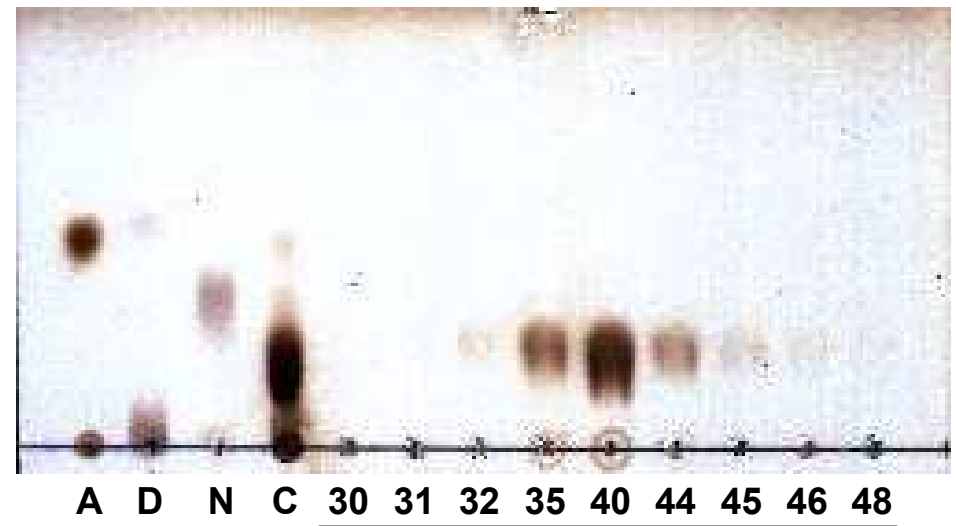

Fraction No.

Fig. 8. TLC analysis of the fractions separated by use of gel-filtration column chromatography.

The product is usually contained in the $30^{\text {th }}$ to $50^{\text {th }}$ fraction eluted during the gel-filtration column chromatography; a typical example is shown. A; lactose, D; CMP-Neu5Ac, N; Neu5Ac, C; 6'-sialyllactose standard.

\subsubsection{Alternative anion-exchange column chromatography method for large-scale purification of 6 '-sialyllactose}

As mentioned in section 4.1.2, a large volume of solution containing 6'-sialyllactose could be prepared by using high cell-density cultures of a genetically engineered E. coli strain. In such cases, we performed an alternative anion-exchange column chromatography process. At the end of the fermentation, the whole culture was permeabilized by autoclaving at $100^{\circ} \mathrm{C}$ for 50 min. The mixture was centrifuged at 7,000 $\mathrm{g}$ for $30 \mathrm{~min}$ and the supernatant containing the oligosaccharides was removed. The $\mathrm{pH}$ of the extracellular fraction was lowered to 3.0 by the addition of a strong cation-exchange resin (Amberlite IR120 $\mathrm{H}^{+}$form, Sigma-Aldrich Japan, Tokyo), and the proteins that were precipitated by this process were removed by centrifugation. The $\mathrm{pH}$ of the clear supernatant was then adjusted to 6.0 by the addition of a weak anion exchanger (Dowex 66 free base form; Sigma-Aldrich Japan) and, after decanting, 
the supernatant was loaded onto a Dowex 1 ( $\mathrm{HCO}_{3}$ form, Sigma-Aldrich Japan) column (ø 5 $x 20 \mathrm{~cm}$ ). After the column was washed with distilled water, the acidic oligosaccharides retained on the Dowex 1 resin were eluted with $100 \mathrm{mM} \mathrm{NaHCO}_{3}$. The eluted fractions containing acidic oligosaccharides were pooled and the $\mathrm{NaHCO}_{3}$ was removed by treatment with Amberlite IR120 $\left(\mathrm{H}^{+}\right.$form) until the $\mathrm{pH}$ reached 3. The $\mathrm{pH}$ was then adjusted to 6.0 with $\mathrm{NaOH}$ and the acidic oligosaccharide fraction was freeze-dried.

\subsubsection{Separation of various sialyl-compounds by using HPLC}

Anion-exchange column chromatography is a powerful method for separating a single mono-sialyloligosaccharide from the other components in the sample solution; however, it is impossible to separate one mono-sialyloligosaccharide from another monosialyloligosaccharide, such as 6'-sialyllactose or 3'-sialyllactose, by using this method. In such cases, HPLC can be used successfully for the separation, as described by Endo et al. (Endo et al., 2009). In this protocol, the HPLC system is equipped with a TSKgel Amide-80 column (particle size $5 \mathrm{~mm}, \varnothing 4.6 \times 250 \mathrm{~mm}$; Tosoh Bioscience), and is run at $40^{\circ} \mathrm{C}$ with a flow rate of $1 \mathrm{mLl} / \mathrm{min}$, and the eluates are monitored with a UV (195 nm) detector. The elution conditions are as follows: 0 to $15 \mathrm{~min}$ isocratic elution with $75 \%$ acetonitrile in 15 $\mathrm{mM}$ potassium phosphate buffer ( $\mathrm{pH}$ 5.2); and 15 to 45 min linear gradient elution with a gradient of $75 \%$ to $50 \%$ acetonitrile in $15 \mathrm{mM}$ potassium phosphate buffer ( $\mathrm{pH} 5.2$ ).

Some examples of HPLC chromatograms produced for sialyl-compounds synthesized as described in section 4.1 are shown in Figure 9.

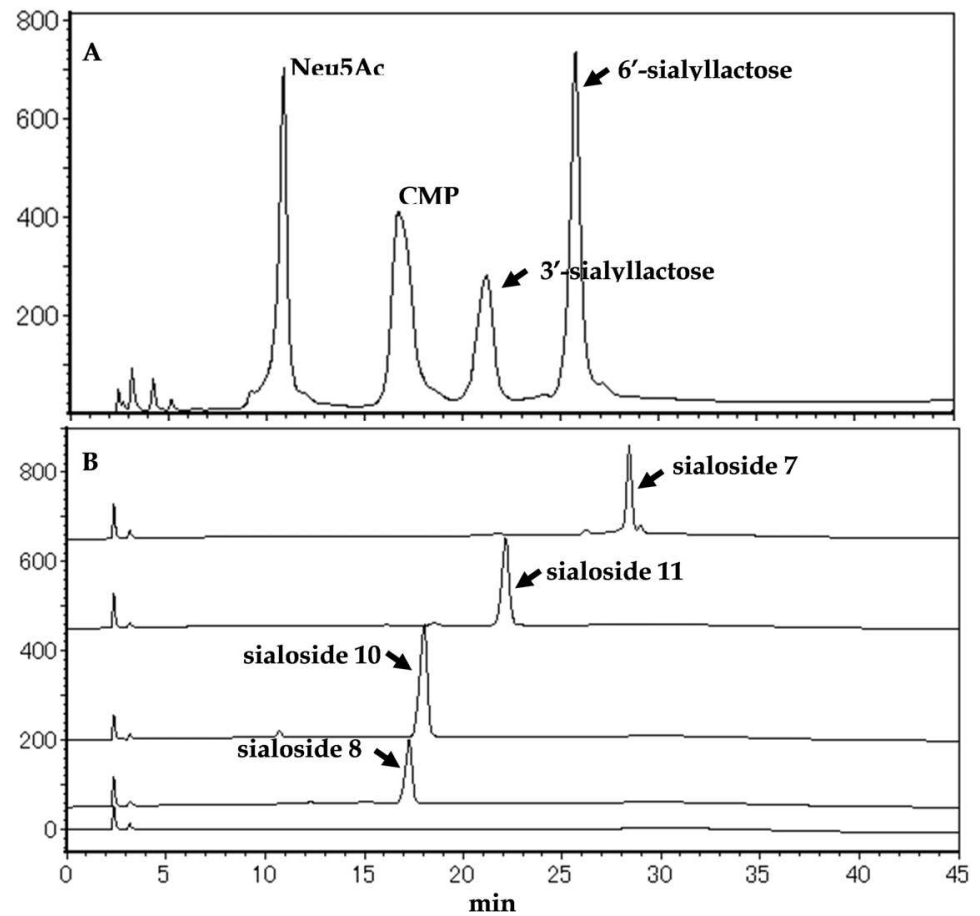

Fig. 9. Chromatograms of some sialyl-compounds. 
The sample solution (150 mL) containing sialyl-compound(s) was separated as described in section 4.2.3. A; an example of the separation of two mono-sialyloligosaccharides, $\mathrm{B}$; examples of the chromatogram of various mono-sialyloligosaccharides.

\section{Conclusion}

It is now possible to produce large amounts of sialyloligosaccharides by using newly developed methods, including chemoenzymatic methods and fermentation methods. It is also possible to produce huge quantities of sialyltransferase enzymes. However, large-scale production of other glycosyltransferases, such as $N$-acetylglucosaminyltransferase or fucosyltransferase, is still difficult. For this reason, it is of great importance to identify enzymes that could be used in the production of other glycosyltransferases and to establish mass-production methods for these enzymes.

\section{Acknowledgment}

The authors would like to thank Ms. Hitomi Kajiwara for her valuable comments and all of their collaborators.

\section{References}

Angata, T., \& Varki, A. (2002) Chemical diversity in the sialic acids and related $\alpha$-keto acids: an evolutionary perspective. Chemical Reviews, Vol.102, Issue 2, (February, 2002), pp.439-469, ISSN: 0009-2665

Connor, R. J.; Kawaoka, Y.; Webster, R. G. \& Paulson, J. C. (1994) Receptor specificity in human, avian, and equine H2 and H3 influenza virus isolates. Virology, Vol.205, Issue 1, (Nobember 15, 1994), pp.17-23, ISSN 0042-6822

Deutscher, M.P. (Ed.)., (1990), Guide to Protein Purification, ACADEMIC PRESS, INC., ISBN 0-12-213585-7, San Diego

Drouillard, S.; Mine, T.; Kajiwara, H.; Yamamoto, T. \& Samain, E. (2010) Efficient synthesis of $6^{\prime}$-sialyllactose, $6^{\prime}, 6$-disialyllactose and $6^{\prime}$-KDO-lactose by metabolically engineered Escherihiae coli expressing a multifunctional sialyltransferase from the Photobacterium sp. JT-ISH-224. Carbohydrate Research, Vol.345, Issue 10, (July 2,2010), pp.1394-1399, ISSN 0008-6215

Endo, S.; Morita, M.; Ueno, M.; Maeda, T. \& Terabayashi, T. (2009) Fluorescent labeling of a carboxyl group of sialic acid for MALDI-MS analysis of sialyloligosaccharides and ganglioside. Biochemical and Biophysical Research Communications, Vol.378, Issue 4, (January 23, 2009), pp.890-894, ISSN 0006-291X

Fierfort, N. \& Samain, E. (2008) Genetic engineering of Escherichia coli for the economical production of sialylated oligosaccharides. Journal of Biotechnology, Vol.134, No.3, (April 30, 2008), pp.261-265, ISSN 0168-1656

Gagneux, P. \& Varki, A. (1999) Evolutionary considerations in relating oligosaccharide diversity to biological function. Glycobiology, Vol. 9, No. 9, (August 1, 1999), pp.747-755, ISSN 0959-6658

Izumi, M. \& Wong, C-H. (2001) Microbial sialyltransferases for carbohydrate synthesis. Trends in Glycoscience and Glycotechnology, Vol.13, No.72, (July, 2001), pp.345360, ISSN 0915-7352 
Kajihara, Y.; Yamamoto, T.; Nagae, H.; Nakashizuka, M.; Sakakibara, T. \& Terada, I. (1996) A novel a-2,6-sialyltransferase: transfer of sialic acid to fucosyl and sialyl trisaccharides. The journal of Organic Chemistry, Vol.61, No.24, (November 29, 1996), pp.8632-8635, ISSN 0022-3263

Kajiwara, H.; Mine, T. \& Yamamoto, T. (2009) Sialyltransferases Obtained from Marine Bacteria. Journal of Applied Glycoscience, Vol.56, No.2, (October 15, 2009), pp.7782, ISSN 1344-7882

Kajiwara, H.; Toda, M.; Mine, T.; Nakada, H.; Wariishi, H. \& Yamamoto, T. (2010) Visualization of Sialic Acid Produced on Bacterial Cell Surfaces by Lectin Staining. Microbes Environ. Vol. 25, No. 3, (September, 2010) pp.152-155, ISSN 1342-6311

Kannagi, R. (2002) Regulatory roles of carbohydrate ligands for selectins in homing of lymphocytes. Current Opinion in Structural Biology, Vol.12, Issue5, (October 1, 2002), pp.599-608, ISSN 0959-440X

Kochibe, N. \& Furukawa, K. (1980) Purification and properties of a novel fucose-specific hemagglutinin of Aleuria aurantia. Biochemistry, Vol.19, No.13, (June, 1980), pp.2841-2846, ISSN 0006-2960

Kunz, C.; Rudloff, S.; Baier, W.; Klein, N. \& Strobel, S. (2000) Oligosaccharides in human milk: structural, functional and metabolic aspects. Annual Review of Nutrition, Vol.20, (July, 2000), pp.699-722, ISSN 0199-9885

Mine, T.; Kajiwara, H.; Murase, T.; Kajihara, Y. \& Yamamoto, T. (2010a) An a2,3sialyltransferase cloned from Photobacterium sp. JT-ISH-224 transfers $N$ acetylneuraminic acid to both O-2 and O-3' hydroxyl groups of lactose. Journal of Carbohydrate Chemistry, Vol.29, Issue 2, ( March, 2010), pp.51-60, ISSN 0732-8303

Mine, T.; Miyazaki, T.; Kajiwara, H.; Naito, K.; Ajisaka, K. \& Yamamoto, T. (2010b) Enzymatic synthesis of unique sialyloligosaccharides using marine bacterial $\alpha$ $(2 \rightarrow 3)$ - and $\alpha-(2 \rightarrow 6)$-sialyltransferases. Carbohydrate Research, Vol.345, Issue 10, (July 2,2010), pp.1417-1421, ISSN 0008-6215

Mine, T.; Kajiwara, H.; Tateda, N.; Miyazaki, T.: Ajisaka, K. \& Yamamoto, T. (2010c) Recombinant $\alpha-(2 \rightarrow 3)$-sialyltransferase with extremely broad acceptor substrate specificity from Photobacterium sp. JT-ISH-224 could transfer $\mathrm{N}$-acetylneuraminic acid to inositols. Carbohydrate Research, Vol.345, Issue 10, (July 2,2010), pp.13941399, ISSN 0008-6215

Paulson, J. C. (1989) Glycoproteins: What are the sugar chains for? Trends in Biochemical Sciences, Vol.14, Issue 7, (July, 1989), pp.272-276, ISSN 0968-0004

Sabesan, S. \& Paulson, J.C. (1986) Combined chemical and enzymatic synthesis of sialyloligosaccharides and characterization by $500 \mathrm{MHz}{ }^{1} \mathrm{H}$ and ${ }^{13} \mathrm{C}$ NMR spectroscopy. Journal of the American Chemical Society, Vol.108, Issue 8, (April, 1986), pp.2068-2080, ISSN 0002-7863

Schauer, R. (2004) Sialic acid: fascinating sugars in higher animals and man. Zoology, Vol.107, Issue 1, (March 16, 2004), pp.49-64, ISSN 0944-2006

Scopes, R.K. (1982), Protein Purification -Principles and Practice, Springer-Verlag, ISBN 0-38790726-2, New York

Shibuya, N.;Tazaki, K.; Song, Z.;Tarr, G. E.;Goldstein,I. J. \& Peumans, W. J. A. (1989) Comparative study of bark lectins from three elderberry (Sambucus) species. Journal of Biochemistry, Vol.106, No.6, (June, 1989), pp.1098-1103, ISSN 0021-924X 
Sujino, K.; Jackson, R.J.; Chan, N.W.C.; Tsuji, S. \& Palcic, M.M. (2000) A novel viral a2,3sialyltransferase (v-ST3Gal I): transfer of sialic acid to fucosylated acceptors. Glycobiology, Vol.10, Issue 3, (March 1, 2000), pp.313-320, ISSN 0959-6658

Suzuki, Y. (2005) Sialobiology of influenza: molecular mechanism of host range variation of influenza virus. Biological \& Pharmaceutical Bulletin, Vol.28, No.3, (March, 2005), pp.399-408. ISSN 0918-6158

Tsukamoto, H.; Takakura, Y. \& Yamamoto, T. (2007) Purification, cloning and expression of an $\alpha$-/ $\beta$-galactoside $\alpha 2,3$-sialyltransferase from a luminous marine bacterium, Photobacterium phosphoreum. Journal of Biological Chemistry, Vol.282, Issue 41, (October 12, 2007), pp.29794-29802, ISSN 0021-9258

Tsukamoto, H.; Takakura, Y.; Mine, T. \& Yamamoto, T. (2008) Photobacterium sp. JT-ISH-224 Produces Two Sialyltransferases, $\alpha-/ \beta$-Galactoside $\alpha 2,3-$ Sialyltransferase and $\beta$ Galactoside a2,6-Sialyltransferase. Journal of Biochemistry, Vol. 143, No.2, (February, 2008), pp.187-197, ISSN 0021-924X

Varki, A. (1993) Biological roles of oligosaccharides: all of the theories are correct. Glycobiology, Vol.3, Issue 2, (April 3, 1993), pp.97-130, ISSN 0959-6658

Vimr, E. R.; Kalivoda, K. A.; Denzo, E. L. \& Steenbergen, S. M. (2004) Diversity of microbial sialic acid metabolism. Microbiology and Molecular Biology Reviews, Vol.68, No.1, (March, 2004), pp.132-153, ISSN 1092-2172

Weis, W.; Brown, J. H.; Cusack, S.; Paulson, J. C.; Skehel, J. J. \& Wiley, D. C. (1988) Structure of influenza virus haemagglutinin complexed with its receptor, sialic acid. Nature, Vol.333, (June 2, 1988), pp.426-431, ISSN 0028-0836

Yamamoto, T. (2006) Bacterial Sialyltransferases. Trends in Glycoscience and Glycotechnology, Vol.18, N0.102, (July, 2006), pp.253-265, ISSN 0915-7352

Yamamoto, T. (2010) Marine Bacterial Sialyltransferases. Marine Drugs, Vol.8, Issue 18, (November 10, 2010), pp.2781-2794, ISSN 1660-3397

Yamamoto, T.; Nakashizuka, M. \& Terada, I. (1998) Cloning and expression of a marine bacterial $\beta$-galactoside $\alpha 2,6$-sialyltransferase gene from Photobacterium damsela JT0160. Journal of Biochemistry, Vol.123, No.1, (January, 1998), pp.94-100, ISSN 0021-924X

Yamamoto, T.; Hamada, Y.; Ichikawa, M.; Kajiwara, H.; Mine, T.; Tsukamoto, H. \& Takakura, Y. (2007) A $\beta$-galactoside $\alpha 2,6$-sialyltransferase produced by a marine bacterium, Pho\&bacterium leiognathi JTSHIZ-145, is active at $\mathrm{pH}$ 8. Glycobiology, Vol.17, No.11, (Nobember, 2007), pp.1167-1174, ISSN 0959-6658

Yamamoto, T.; Nagae, H.; Kajihara, Y. \& Terada, I. (1998) Mass production of bacterial $\alpha 2,6-$ sialyltransferase and enzymatic syntheses of sialyloligosaccharides. Bioscience, Biotechnology, and Biochemistry, Vol.62, No.2 , (Febraury, 1998), pp.210-214, ISSN 0916-8451

Yu, H.; Chokhawala, H.; Karpel, R.; Yu, H.; Wu, B.; Zhang, J.; Zhang, Y.; Jia, Q. \& Chen, X. (2005) A multifunctional Pasteurella multocida sialyltransferase: a powerful tool for the synthesis of sialoside libraries. Journal of the American Chemical Society, Vol.127, Issue 50, (November, 2005), pp.17618-17619, ISSN 0002-7863 


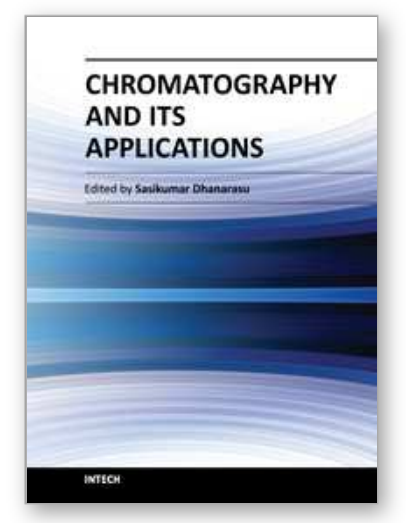

\author{
Chromatography and Its Applications \\ Edited by Dr. Sasikumar Dhanarasu
}

ISBN 978-953-51-0357-8

Hard cover, 224 pages

Publisher InTech

Published online 16, March, 2012

Published in print edition March, 2012

Chromatography is a powerful separation tool that is used in all branches of science, and is often the only means of separating components from complex mixtures. The Russian botanist Mikhail Tswett coined the term chromatography in 1906. The first analytical use of chromatography was described by James and Martin in 1952 , for the use of gas chromatography for the analysis of fatty acid mixtures. A wide range of chromatographic procedures makes use of differences in size, binding affinities, charge, and other properties. Many types of chromatography have been developed. These include Column chromatography, High performance liquid chromatography (HPLC), Gas chromatography, Size exclusion chromatography, Ion exchange chromatography etc. In this book contains more details about the applications of chromatography by various research findings. Each and every topics of this book have included lists of references at the end to provide students and researchers with starting points for independent chromatography explorations. I welcome comments, criticisms, and suggestions from students, faculty and researchers.

\title{
How to reference
}

In order to correctly reference this scholarly work, feel free to copy and paste the following:

Toshiki Mine and Takeshi Yamamoto (2012). Purification of Marine Bacterial Sialyltransferases and Sialyloligosaccharides, Chromatography and Its Applications, Dr. Sasikumar Dhanarasu (Ed.), ISBN: 978-95351-0357-8, InTech, Available from: http://www.intechopen.com/books/chromatography-and-itsapplications/purification-of-marine-bacterial-sialyltransferases-and-sialyloligosaccharides

\section{INTECH}

open science | open minds

\section{InTech Europe}

University Campus STeP Ri

Slavka Krautzeka 83/A

51000 Rijeka, Croatia

Phone: +385 (51) 770447

Fax: +385 (51) 686166

www.intechopen.com

\section{InTech China}

Unit 405, Office Block, Hotel Equatorial Shanghai

No.65, Yan An Road (West), Shanghai, 200040, China

中国上海市延安西路65号上海国际贵都大饭店办公楼 405 单元

Phone: +86-21-62489820

Fax: $+86-21-62489821$ 
(C) 2012 The Author(s). Licensee IntechOpen. This is an open access article distributed under the terms of the Creative Commons Attribution 3.0 License, which permits unrestricted use, distribution, and reproduction in any medium, provided the original work is properly cited. 